\title{
A case study on safety assessment of construction project in Bangladesh
}

\author{
Md. Mehrab Hossain, Shakil Ahmed* \\ Khulna University of Engineering \& Technology, Department of Building Engineering and Construction \\ Management, Khulna, Bangladesh
}

\begin{abstract}
Construction industry plays a vital role in the economic development of any country. As construction industry is less mechanized and more labor intensive, construction workers are backbone of this industry. So the major consideration is ensuring workers safety during construction. This paper is aimed to examine the current safety status and identify the main causes of not practicing safety rules in the construction sites in Bangladesh. The study was conducted in three stages. Firstly, the existing rules and regulations of construction safety were studied. Secondly physical survey was conducted among the ongoing construction sites. Thirdly factors that influence the safety performance in construction sites were identified by conducting questionnaire survey and ranked based on Factor Index (FI). This study found 20 major causes those affect the construction safety performance at job site. According to the physical survey data, it was obvious that workers were working without PPE and fall protective system. From the data analysis, the main cause of not practicing safety rules are lack of enforcement of safety rules and regulations, lack of safety awareness among the construction stakeholder and lack of safety training. The survey results may help the authorities to increase the awareness of safety and enforce the construction safety rules in the next project approach.
\end{abstract}

\section{Keywords}

Construction industry; BNBC; BLA; Safety performance; PPE; Factor index

Received: 28 November 2018; Accepted: 20 December 2018

ISSN: 2630-5771 (online) @ 2018 Golden Light Publishing All rights reserved.

\section{Introduction}

Construction industry is considered as one of the most dominating sources of economic growth and development of any country [1]. It also have a great contribute to the Bangladesh national economy [2]. Construction involves a little percentage of the overall workforce. But it is regarded as the most hazardous industry due to its unique nature and the safety record of building construction industry has always been poor [3-5]. Within many business developments sector construction industry is one of the largest and rapidly growing industrial sectors. This industry is considered as the most dangerous industry in recent year $[6,7]$. The incidence rate for both fatal and non-fatal accidents causing death, injuries and illnesses exceeds that of numerous different enterprises. At least 108 thousand workers are killed on site every year, which represents about $30 \%$ of all occupational deaths [8]. The risks are 3 to 6 times more likely than any other occupation [9]. More than 26,000 U.S. construction workers in the past two decades have died at work. This equates that in every working day five construction workers die approximately [10]. Of these fatalities, $40 \%$ involved incidents that is related to falls from height $[11,12]$. In Turkey, health and safety in

* Corresponding author

Email: ashakilmondol@gmail.com 
construction is also considered as the primary problem [13]. Tiwari et al. [14] shows the low level of safety practice and even not appear in various Indian construction site. Malaysian construction industry also suffer a lot for the safety issues in construction sites [15].

Being a developing country construction industry is growing rapidly in Bangladesh. It represents 7.6 percent of Bangladesh's gross domestic product (GDP) and employs more than 3.3 million people $[16,17]$. There are more than a thousand companies in Bangladesh who are involved in the construction business [18]. But in Bangladesh safety management issues are characterized as a very poor rate. From the literature review of this study it is clear that more than 800 death is occurred in construction sites during the phase of 2008 to 2013 [19]. In Bangladesh more than $40 \%$ workers die due the falling from height. In the case of accident construction industry could have been in highest position, but the accidents occurred in Rana Plaza during 2013 had resulted in 1331 deaths [19]. As a result the fatalities rate of workers in garments sector is the highest position. If we skip the fatalities rate in garments sector, construction industry is placed in highest rank. A safe and constructive working environment decreases the risks of heavy accidents at work, sickness and lower costs for the total construction.

The government enacted the following Act/Code at the national level to ensure health and safety of workers in construction sector:

* BLA 2006 (Bangladesh Labour Act 2006)

* BNBC 2006 (Bangladesh National Building Code 2006).

These regulatory documents have provisions to focus the welfare of construction workers. In order to protect the rights of the workers, the following authorities are entrusted with the duty according to the provision respectively.

* The Department of Inspection for Factories and Establishment - legal authority to enforce BLA 2006.

* RAJUK (Rajdhani Unnayan Kattripakkha or the Capital Development Authority) - legal authority to enforce BNBC 2006 and to take legal actions against the violators of safety laws specifically for construction sector.

No health and safety law was applied to the construction sector as there was no existing law before November 2006. In November 2006, the Bangladesh Labour Act 2006 (BLA 2006) and the Bangladesh National Building Code 2006 (BNBC 2006) were first introduced. These rules and regulations contain health and safety provision relevant to the construction sector.

The Bangladesh Labour Act 2006 (BLA 2006) includes all types of labour that are involved in any type of work that are related to GDP of the country. On the contrary Bangladesh National Building Code 2006 (BNBC 2006), specifically deals with the labour safety of the building construction sector.So the author wants to find out what are the actual onsite scenario and what are the reasons behind the labor death or injury in construction sites in Bangladesh against BNBC and BLA.

The prime objectives of this study are as follows:

I. To investigate the current safety status in building construction in Bangladesh.

II. To analyze the safety factors those influence the safety performance in construction sites.

\section{Methodology}

In order to find out the actual scenario of the workers safety, a broad literature review was conducted from published and unpublished documents, newspapers, internet, journals, articles, reports, newsletters, and OSHE (Bangladesh Occupational Safety, Health and Environment Foundation) statistics. At the same time existing rules and regulations about construction safety in Bangladesh were studied. Then the questionnaire was designed from the gathered information and survey was conducted among different construction sites. After that the major causes were ranked based on factor index.

\subsection{Questionnaire design}

There are 20 factors were selected from literature review and experts opinion which may cause the fatalities in construction sites. A well-structured 
close-ended questionnaire was designed in order to gather information from building construction sites in Bangladesh. The questionnaire was designed in such a way that there was no biasness. In most cases, the respondents (the contractor, engineers, project managers and the workers) were used to answer with respect to four points of scaling. So the conventional four points scaling were selected to design the questionnaire:

- Very important or very serious effect (4 points)

- Important or serious effect (3 points)

- Moderate important or moderate effect (2 points)

- Least important or least effect (1 point)

- No effect (0 point)

\subsection{Data collection and analysis}

The engineers, contractors, project managers and labors were included in this survey. The opinion of university teachers related to construction field was also included here. The questions were thrown in separately within the worker as well as engineer, project manager and contractor. Authors visited 17 construction sites and total 67 respondent's data were observed. Table 1 shows the demographic information of respondents. At the time of the whole survey various complications and impediments were faced. Although the worker and engineer were shown their willingness to give the answer of the question, the contractor, project manager and related person of contractors were shown unwillingness to take part in the survey. Some on-going construction sites were visited physically so that the given data from construction stakeholder could be checked in accordance with the actual evidence present in the sites.

This section includes the preferences of respondents on main factors influencing safety management on construction sites. The data was analysed by using the following formula:

$T W V=\sum_{i=1}^{4} P i V i$

Where, TWV $=$ the total weight value; $\mathrm{Pi}=$ the number of respondents rating the safety factors; $\mathrm{Vi}$ $=$ the weight assigned to each factor $\mathrm{i}$.
Table 1. Demographic characteristics of respondents

\begin{tabular}{|c|c|c|}
\hline Demographic Characteristics & Freq. & Percent., $\%$ \\
\hline \multicolumn{3}{|l|}{ Sex } \\
\hline Male & 47 & 70 \\
\hline Female & 20 & 30 \\
\hline \multicolumn{3}{|l|}{ Age } \\
\hline$\leq 20$ years old & 11 & 17 \\
\hline 21-30 years old & 21 & 31 \\
\hline $31-40$ years old & 22 & 33 \\
\hline$\geq 40$ years old & 13 & 19 \\
\hline \multicolumn{3}{|l|}{ Location } \\
\hline Dhaka Division & 15 & 22 \\
\hline Rajshahi and Rangpur Division & 13 & 15 \\
\hline Chittagong Division & 10 & 18 \\
\hline Sylhet Division & 8 & 11 \\
\hline Khulna and Barisal Division & 21 & 31 \\
\hline
\end{tabular}

The factor index (FI) for each factor was derived by dividing TWV by the number of respondents (n) and the mean of FI was also determined by the following equation:

$F I=\sum_{i=1}^{4} \frac{P i V i}{n}$

Then the mean of factor index $(\mu)$ was calculated and deviation was found by using the following equation:

Deviation $=(\text { FI- } \mu)^{2}$

In the case of ranking the factor index was used and the maximum value of factor index was considered as 1 st and gradually decreasing the rank respectively.

\section{Results and discussions}

\subsection{Physical survey results}

To assess the real scenario of construction safety, the physical survey was conducted in different construction sites in Bangladesh.

From Fig. 1 it is shown that the labors are working without any fall protective tools. According to the BNBC-2006, the slab must be guarded against falling. Not only the slab but also any opening in walls, slabs as well as edge of the slab and staircases must be guarded against falling. 
But the actual scenario during construction does not satisfy the labour safety regulations. As a result the proximity of fatalities is increasing day by day.

From the Fig. 2, it is clear that the labors are working without hand gloves, safety boots. According to the BNBC-2006, the area where personal protective equipment is necessary must be used. In this figure the necessity of boots, hand gloves are essential, but no uses was found during construction. The labors were asked why they were not using boots, hand gloves. The labor claimed against contractor for not providing the safety boots, helmets, hand gloves and other protective equipment. Contractor is the main responsible person to ensure the safety of construction workers. Fig. 2 shows such kind of working environment that does not satisfy the BNBC-2006. As a result the workers are facing skin diseases and other body injuries happen. As workers are only responsible person of their family, their injury turn their family into more poverty.

When we conducted the physical survey, it was observed that the workers were painting and cutting tiles without eye protective equipment, gloves and respiratory protection which is shown in Figs. 3 and 4. In spite of having the regulation for eye protection for labor, the contractor violates the rules. Impact hazards include flying objects such as chips, fragments, particles, sand and dirt. These hazards typically result from tasks like chipping, grinding, machining, masonry work, woodworking, sawing, drilling, chiseling, powered fastening, riveting and sanding. These objects or sparks are usually very small but can cause serious eye damage such as punctures, abrasions and contusions. Serious injury may be happened as workers are not provided the eye protective tools.
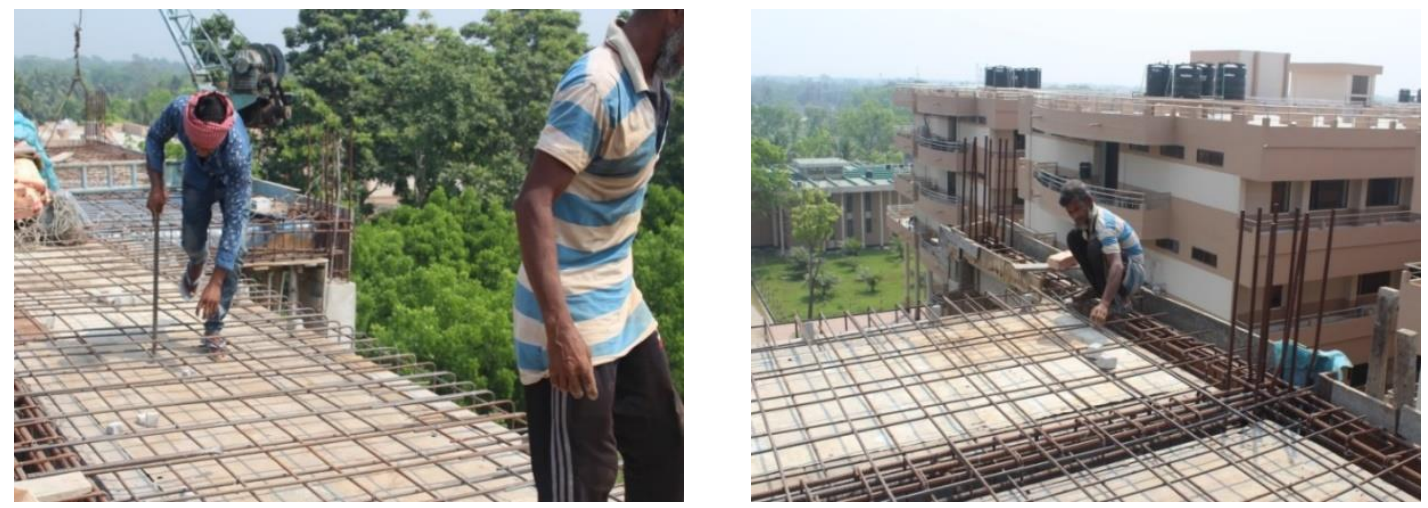

Fig. 1. Labor working without any fall protective guardrail system
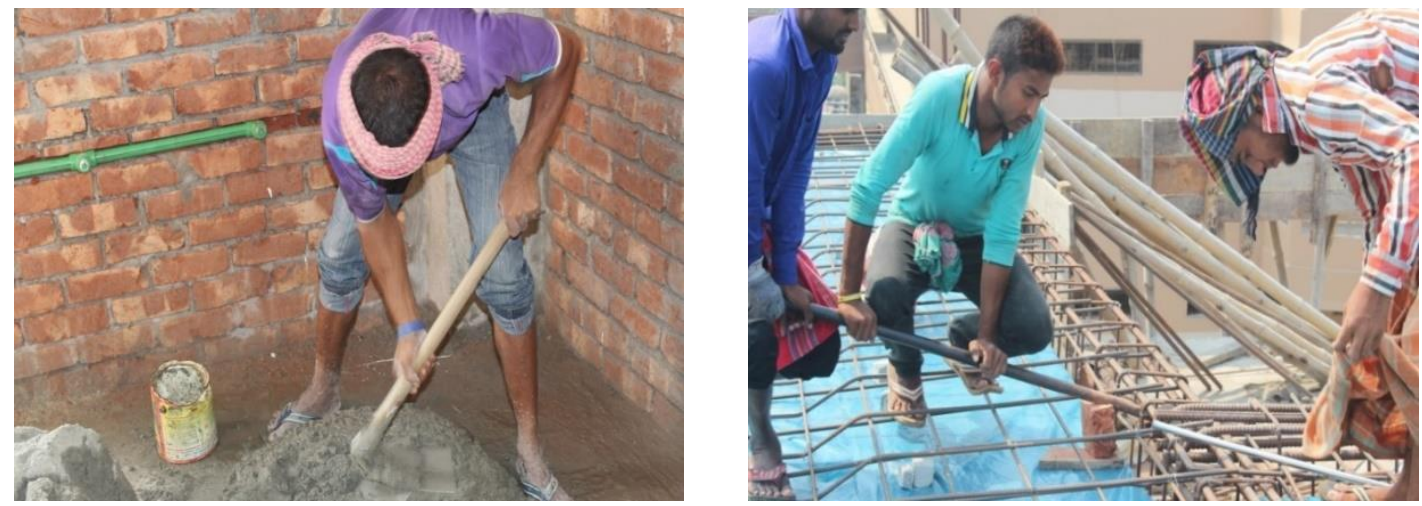

Fig. 2. Worker working without safety boots, hand gloves, head protection 

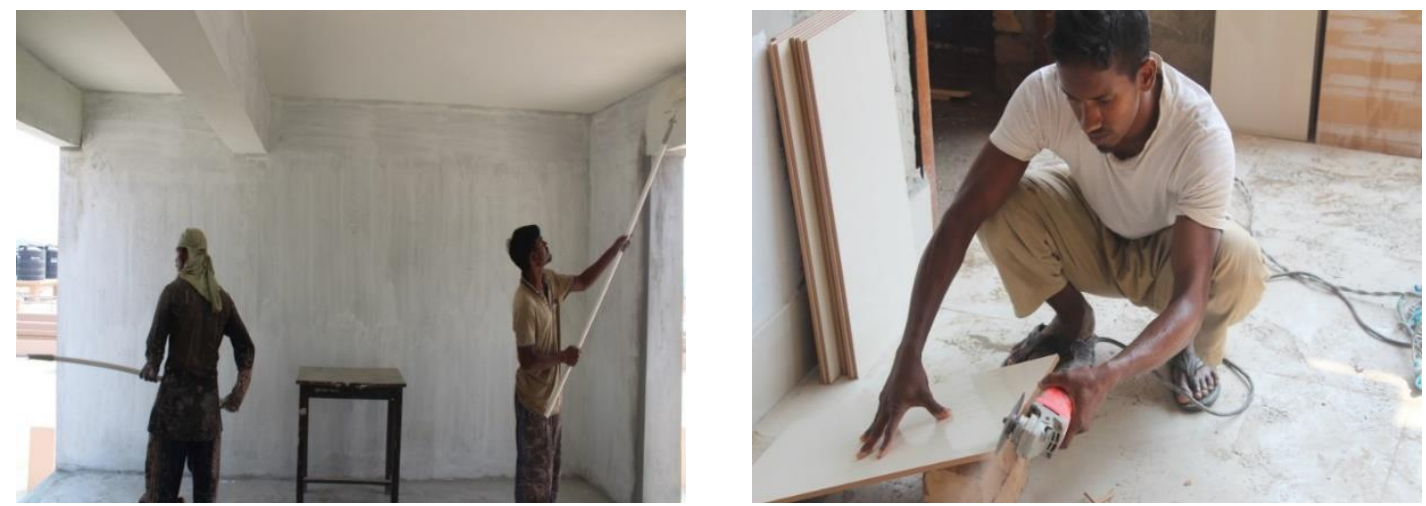

Fig. 3. Labour working without hand gloves, eye protective tools during painting \& cutting
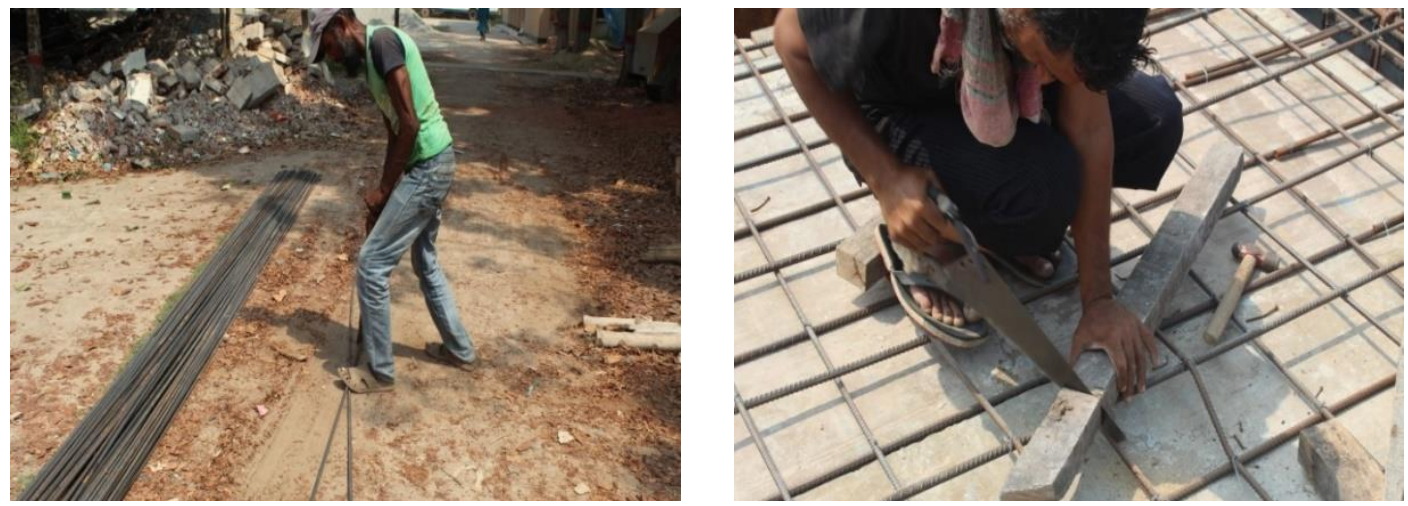

Fig. 4. Labor working without protective measures during bending rod \& cutting wood

In the case of stair and lift, it is essential that the protection against falling must be needed according the BNBC-2006. But the observation resulted that there was no fall protective measurement during construction which is shown in Fig. 5. It was observed that the safety belt was provided by contractor but workers were not using during lift installation. As a result, workers and other related person of construction may experience in hazard. How safety rules are avoided in the construction project in shown in Figs. 5 and 6 in the stair and lift core section. As a result, the workers may fall from height and their life may be lost.

According to the Fig. 7 it is clear that the workers are working without helmets, hand gloves which were not observed during physical survey. Eye protection system is very poor. But the BNBC says that the proper safety measurement is needed during lift installation. Physical survey showed that the contractor violates the building construction regulation. Having no skin protection, eye protection, the sparking resulting from welding may harm the skin which may lead to skin cancer. As the intensity of light was very high, the eye may be damaged due to the lack of safety. Fig. 8 shows the uncovered and unprotected hazardous materials with no safety measure that is the most crucial potential factor of influencing accident and fatalities in results.

The Fig. 8 shows that the electrical wires are kept randomly which may cause the electrocution. In our country more than $40 \%$ worker die due to electrocution. On the other hand the coil spreads spark which was uncovered. As a result the proximity of happening fatalities is increasing day by day. Sometimes workers do not get any proper treatment if injury happens and workers bear their treatment cost for his own. No compensations are provided to the workers for injury and loss of life. 

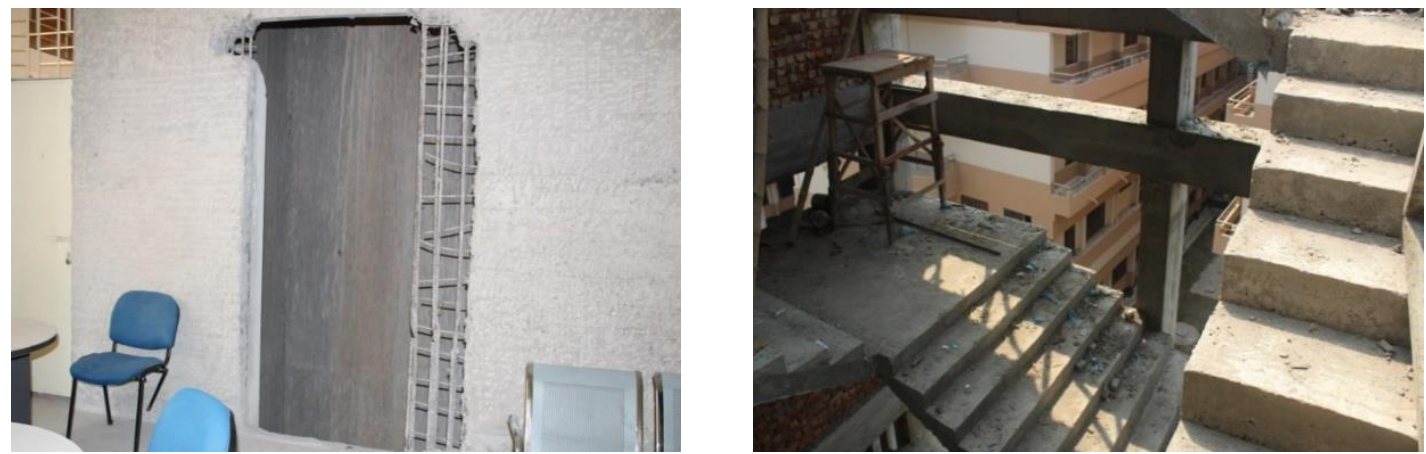

Fig. 5. Unprotected lift core and staircase
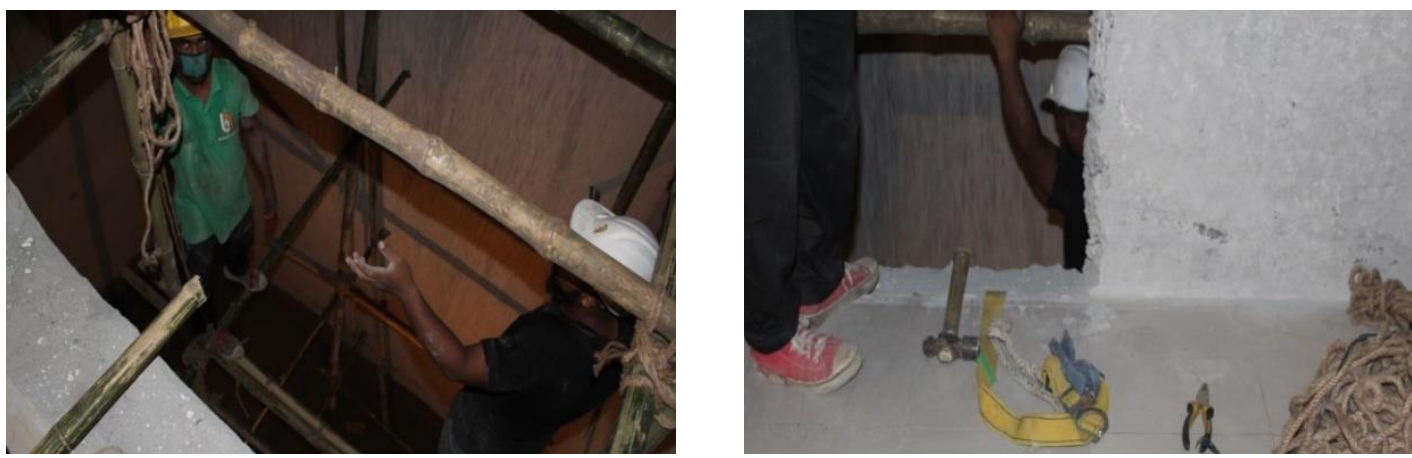

Fig. 6. Working environment without fall protective system and safety belt was provided which was not used
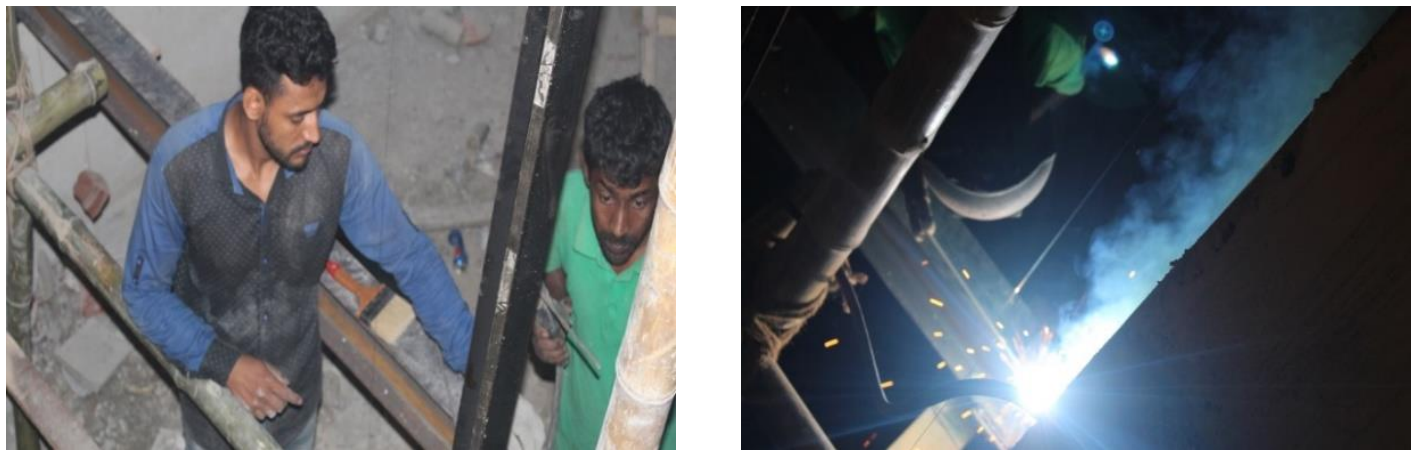

Fig. 7. Workers working without hand gloves, helmets and poor eye protection during welding in lift installation
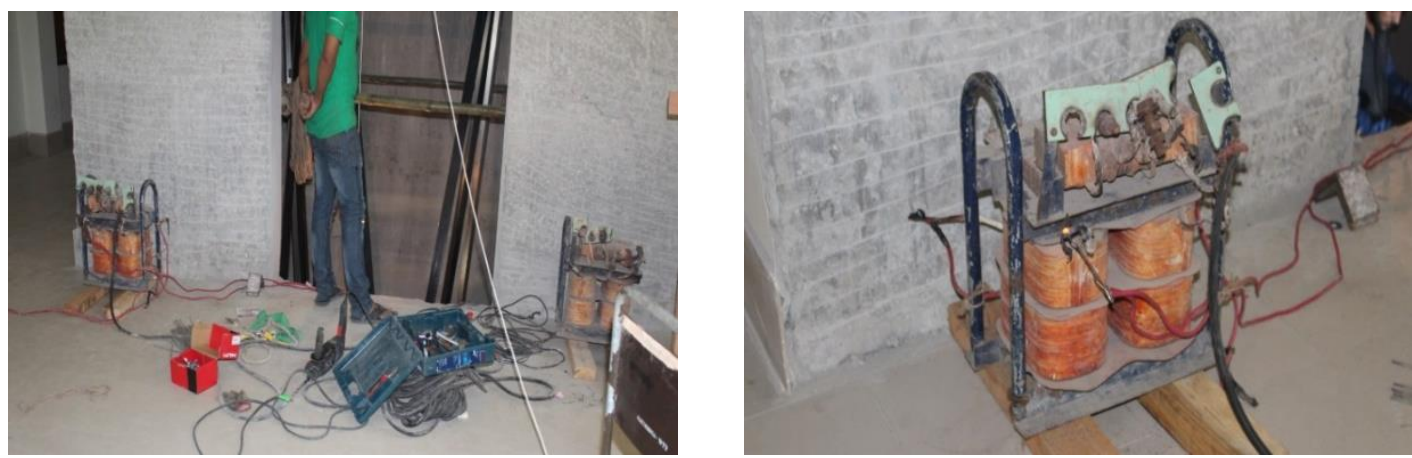

Fig. 8. Electrical wires and equipment are kept in hazardous condition 


\subsection{Current construction safety status}

After completing the physical survey during construction the workers were asked some question. About 67 numbers of respondents were participated in this questionnaire. They were trying to say the actual scenario but sometimes they felt afraid. They were asked about the reason of fear. They answered that the source of income of their family was only labouring and they felt to loss their work if they would give the actual information. Some workers present in the onsite told that they were experienced small or large accident where they did not get the proper treatment and compensation. Even they were not allowed to take rest to recover from the injury.

According to the BLA (Bangladesh Labour Act)2006 and BNBC-2006, the facilities and safety which is mentioned in above for workers must be provided. But there was no application in practical field. From Table 2 it is found that the personal protective equipment (PPE) is not practicing yet. This is the responsibility of contractor to provide the all safety equipment to the workers in order to build up a safe construction environment. The workers said the author that when the inspector came to visit the existing condition for reporting, they are only asked if any faults found or lack of accuracy. They also added that the inspector did not asked why they were not using boots, hand gloves, helmets etc. From the conversation they thought that inspector has lack of awareness about workers safety. In the case of pure water, washing, bathing, fencing floor opening, clean and sanitary latrines, the facilities were very poor which is mentioned in above.

\subsection{Main reasons/factors that influence the safety performance}

Now which are main reasons that influence safety performance which has been mentioned in Fig. 9 is a main issue. In order to find out the answer of this question the survey was conducted among workers, engineers, project managers and contractors in Bangladesh. Total 67 numbers of respondents participated in this survey and question was thrown to the respondents. Some participants tried to skip the main point but they were shown the legal evidence which were found from the qualitative survey. The main reason was then ranked based on the factor index.

The Table 3 and Fig. 10 show the factor index of each factor. The main reasons of not practicing construction safety were identified based on factor index. The higher the factors index the higher the impact. According to the Table 2 it is shown that the first and main reason of not practicing construction safety is the shortage of enforcement of safety regulation. In Bangladesh the whole responsibility to enforce the construction safety regulation according to BNBC 2006 is upon RAJUK (Capital Development Authority). But the lack of enforcement of safety rules and lack of punishment of contractor and owner turns the construction sites as more hazardous.

The second main reason is the lack of safety awareness among the top management, contractor as well as workers. Workers do not feel the necessity of safety for their own. They do not aware what happen if the construction safety is absent. They do not understand about the fatalities in construction. As a result the number of fatalities is increasing tremendously. Not only the workers but also the contractor and top management are not aware about construction safety. The third main reason is the lack of safety training among the site manager, contractor's agent and workers. There is no safety policy, safety program and lack of onsite safety training. As a result workers cannot know the serious impact of accident and rate of construction fatalities is increasing.

Table 2. The main safety and facilities for workers which are not practicing at Bangladesh

\begin{tabular}{lccc}
\hline Item & Yes & No & $\begin{array}{c}\text { Percent for } \\
\text { not practicing }\end{array}$ \\
\hline Pure water supply & 20 & 5 & $20 \%$ \\
Clean and sanitary latrines & 5 & 20 & $80 \%$ \\
$\begin{array}{l}\text { Facilities of washing and } \\
\text { bathing }\end{array}$ & 17 & 8 & $32 \%$ \\
Availability of first aid box & 0 & 25 & $100 \%$ \\
Secure covering and & 0 & 25 & $100 \%$ \\
fencing of floor opening & 0 & 25 & $100 \%$ \\
Head protection & 0 & 25 & $100 \%$ \\
Foot protection & 0 & 25 & $100 \%$ \\
Hand protection & 0 & 25 & $100 \%$ \\
Eye protection & 0 & 25 & $100 \%$ \\
Face protection & 0 & 25 & $100 \%$ \\
Fall protection & 0 & 25 & $100 \%$ \\
Ear protection & & & \\
\hline
\end{tabular}




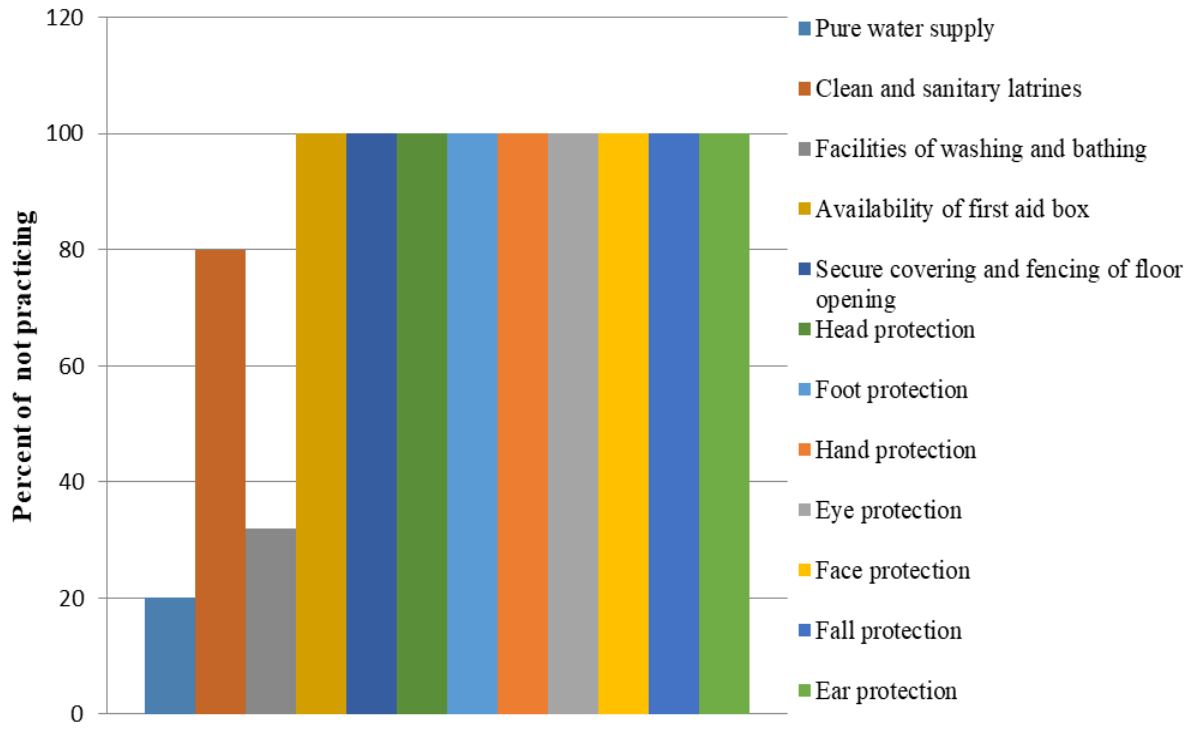

Type of protection and other facilities stated in BLA and BNBC-2006

Fig. 9. Current safety status in construction sites at Bangladesh

Table 3. The main factors that influence construction safety performance at Bangladesh

\begin{tabular}{lccccc}
\hline Type of Safety Factors & TWV & FI & Rank & Mean Deviation & $(\text { FI- } \mu)^{2}$ \\
\hline Lack of attention of top management & 150 & 4.054 & 8 & 0.345 & 0.119 \\
Lack of personal care & 147 & 3.972 & 9 & 0.263 & 0.069 \\
Lack of safety awareness & 171 & 4.621 & 2 & 0.912 & 0.831 \\
Shortage of enforcement of safety regulations & 175 & 4.729 & 1 & 1.02 & 1.04 \\
Lack of safety training & 169 & 4.567 & 3 & 0.858 & 0.736 \\
Errors in scaffolding fixing & 122 & 3.297 & 14 & -0.412 & 0.169 \\
Lack of coordination of top management & 152 & 4.108 & 7 & 0.399 & 0.159 \\
Shortage of safety sign & 114 & 3.081 & 17 & -0.628 & 0.394 \\
Communication gap & 107 & 2.891 & 19 & -0.818 & 0.669 \\
Errors in equipment & 115 & 3.108 & 16 & -0.601 & 0.361 \\
Safety culture & 166 & 4.486 & 4 & 0.777 & 0.603 \\
Lack of budget for labor safety & 164 & 4.432 & 5 & 0.723 & 0.522 \\
Lack of expertise knowledge & 135 & 3.648 & 11 & -0.061 & 0.003 \\
Errors in inspection & 141 & 3.811 & 10 & 0.101 & 0.01 \\
Lack of safety policy & 117 & 3.162 & 15 & -0.547 & 0.299 \\
Lack of coordination between project participants & 130 & 3.513 & 12 & -0.196 & 0.038 \\
Emphasize the temporary purposes & 109 & 2.945 & 18 & -0.764 & 0.583 \\
Errors in decision making & 95 & 2.567 & 20 & -1.142 & 1.304 \\
Contractor's proximity to gain excess profit & 161 & 4.351 & 6 & 0.642 & 0.412 \\
Lack of emergency steps & 129 & 3.486 & 13 & -0.223 & 0.049 \\
\hline
\end{tabular}




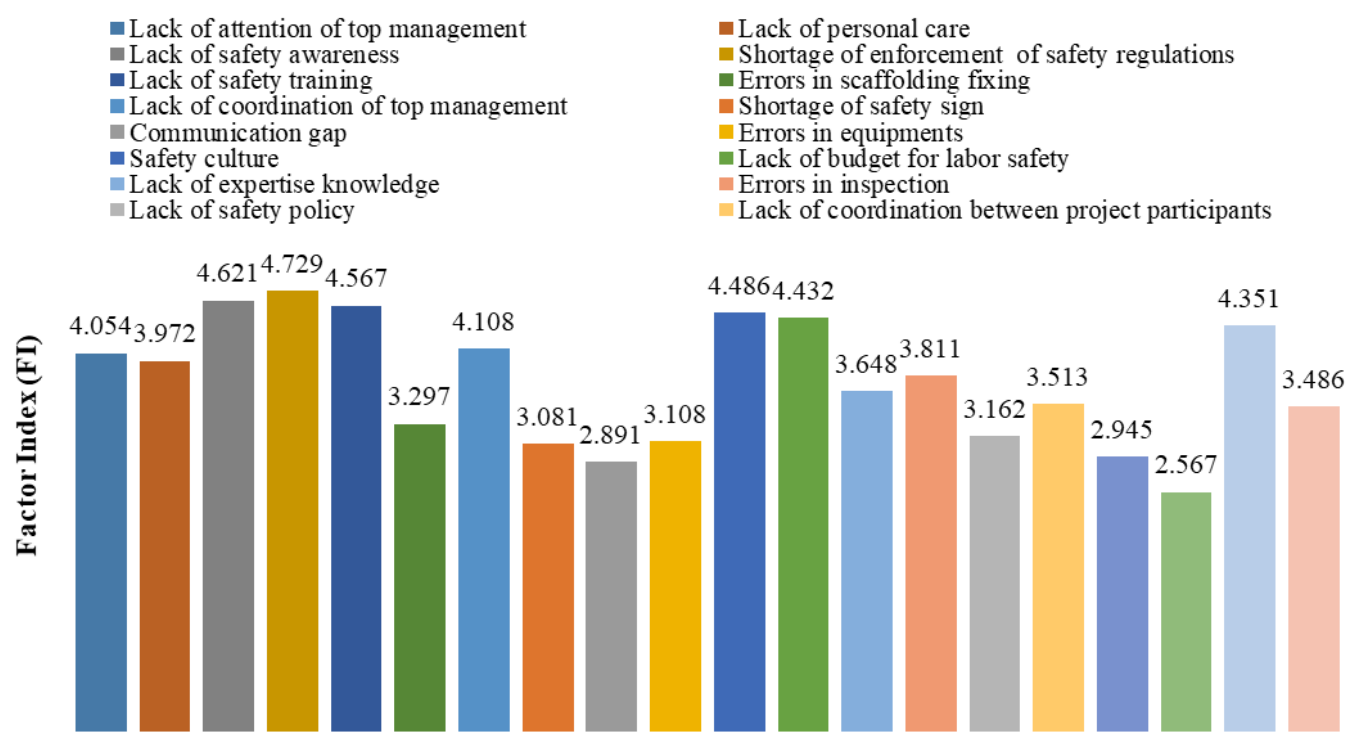

Type of factors that affect construction safety performance

Fig 10. Reasons for not practicing construction safety at Bangladesh.

\section{Conclusions \& recommendations}

Raising the standard of living of people is related to the development of a country. Without building infrastructures such as modern commercial and residential centres, this is not possible and hence construction industry has considered as a very dominating sector. The safety condition in the construction sites is comparatively poor which was found by the survey and this industry is experienced by high fatality rates due to negligence of safety issues.

The summary of results and discussion are as follows:

- Workers are not provided personal protective equipment (PPE) according to the data analysis and from physical survey.

- In the case of fall from height, there is no protective measurement for the workers. But the working environment is running in this way from the beginning.

- The main reason for not practicing safety rules are lack of enforcement of safety laws, lack of safety awareness among the construction stakeholder and lack of safety training respectively.
The recommendations that help the future studies are as follows:

- This survey was conducted at Bangladesh around five construction sites. The additional geographical area can be surveyed so that the result will be obtained more accurately.

- The correlation between construction stakeholder and causes of not practicing safety rules can be added as additional parameter.

- Other statistical tools such as SPSS can be tried for analysis to get a comparison of the results.

\section{References}

[1] Berardi U. A cross-country comparison of the building energy consumptions and their trends. Resources, Conservation and Recycling 123 (2017) 230-241.

[2] Ahmed S., Hoque M.I., Islam M.H., Hossain M. A Reality Check of Status Level of Worker against Skilled Worker Parameters for Bangladeshi Construction Industry. Journal of Civil Engineering and Construction 7(3) (2018) 132-132.

[3] Friend M.A., Kohn J.P. Fundamentals of occupational safety and health. Rowman \& Littlefield 2018. 
[4] Hollnagel E. Safety-I and Safety-II: the past and future of safety management. CRC Press 2018.

[5] Kibert C.J. Sustainable construction: green building design and delivery. John Wiley \& Sons 2016.

[6] Guo H., Yu Y., Skitmore M. Visualization technology-based construction safety management: a review. Automation in Construction 73 (2017) 135-144.

[7] Ahmed S. Barriers to implementation of building information modeling (BIM) to the construction industry: a review, Journal of Civil Engineering and Construction 7(2) (2018) 107-113.

[8] Bourmpoula V., Kapsos S., Pasteels J.-M. ILO labour force estimates and projections: 1990-2050 (2015 edition), ILO Geneva 2015.

[9] ILO, Construction: a hazardous work, 2015, 2015. http://www.ilo.org/safework/areasofwork/hazardo us-work/WCMS_124597/lang--en/index.htm.

(Accessed April 7, 2018 2018).

[10] Kabir Q.S., Watson K., Somaratna T. Workplace safety events and firm performance, Journal of Manufacturing Technology Management 29(1) (2018) 104-120.

[11] Zhang S., Teizer J., Lee J.-K., Eastman C.M., Venugopal M. Building information modeling (BIM) and safety: Automatic safety checking of construction models and schedules, Automation in Construction 29 (2013) 183-195.

[12] Ahmed S., Islam H., Hoque I., Hossain M. Reality check against skilled worker parameters and parameters failure effect on the construction industry for Bangladesh. International Journal of Construction Management (2018) 1-10.

[13] Ulubeyli S., Kazaz A., Er B. Health and safety perception of workers in Turkey: a survey of construction sites. International Journal of Occupational Safety and Ergonomics 20(2) (2014) 323-338.

[14] Tiwary G., Gangopadhyay P. A review on the occupational health and social security of unorganized workers in the construction industry. Indian Journal of Occupational and Environmental Medicine 15(1) (2011) 18.

[15] Bust P.D., Gibb A.G., Pink S. Managing construction health and safety: migrant workers and communicating safety messages. Safety Science 46(4) (2008) 585-602.

[16] BBS, Report on Labour Force Survey, Dhaka, 2018.
[17] Ahmed S., Sobuz M.H.R., Haque M.I. Accidents on construction sites in Bangladesh: A review, 4th International Conference on Civil Engineering for Sustainable Development (ICCESD 2018), KUET, Khulna, Bangladesh, 2018, pp. 9-11.

[18] Dewri L., Amin M., Sen M., Faridi R. A comprehensive study on the real estate sector of Bangladesh, Real Estate and Housing Association of Bangladesh (2012) 1-83.

[19] Jamal M.U.A.M. Safety management issues in construction industry of Bangladesh, Civil Engineering, Bangladesh University of Engineering \& Technology, Dhaka, Bangladesh, 2015. 